\title{
Unmarked individuals in mark-recapture studies: comparisons of marked and unmarked southern elephant seals at Marion Island
}

\author{
W. Chris Oosthuizen*, P.J.Nico de Bruyn, Marthán N. Bester \\ Running head: Unmarked individuals in mark-recapture studies \\ Mammal Research Institute, Department of Zoology and Entomology, University of Pretoria, Private Bag X20, \\ Hatfield, Pretoria, 0028, South Africa \\ *Corresponding author, email: wcoosthuizen@zoology.up.ac.za
}

\begin{abstract}
The presence of unmarked individuals is common in mark-recapture study populations, however, their origin and significance in terms of population dynamics remain poorly understood. At Marion Island, southern Indian Ocean, where virtually all southern elephant seal Mirounga leonina pups born annually (1983 - 2008) were marked in a long-term markresight study, large numbers of unmarked seals occur. Unmarked seals originate from either marker (tag-) loss or from immigration. We aimed to identify patterns in the occurrence of marked and unmarked individuals that will allude to the possible origin and significance of the untagged component of the population, predicting that tag-loss will add untagged seals to mainly adult age categories whereas migrating untagged individuals will be mostly juveniles. We fitted a generalized linear model using the factors month, year and age class to explain the relative abundance of untagged seals (tag-ratio) from 1997 to 2009. Site usage of untagged seals relative to tagged seals was assessed using a binomial test. Untagged seals, predominantly juveniles, were present in the highest proportions relative to tagged seals during the winter haulout (tagged seals/total seals $<0.3$ ) and the lowest proportion (approximately 0.5 ) during the female breeding haulout, increasing in relative abundance from 1997 to 2009. Untagged seals were distributed evenly across suitable haulout sites while tagged seals displayed high local site fidelity and occurred in greater numbers at or near large breeding beaches. Untagged seals are considered to be mostly migrant seals that disperse from other islands within the southern Indian Ocean and haul out at Marion Island during non-breeding haulouts in particular. Some of these seals immigrate to the breeding population, which can be a key component of the local population dynamics. We emphasise the need for mark-recapture
\end{abstract}


studies to evaluate the role of the unmarked component of a population, thereby inducing a more confident estimation of demographic parameters from the marked sample.

Keywords: dispersal, distribution, mark-resight, Mirounga leonina, unmarked

\section{Introduction}

A thorough understanding of population processes and ecosystem functioning is vital in a world where biodiversity is threatened by climate change, habitat loss, overexploitation, or impacts from introduced species to name a few (e.g., Caughley 1994; Roberts and Hawkins 1999). Time-series abundance data allow assessment of not only the conservation status, but also the intrinsic and extrinsic factors driving population trends of species (McMahon et al. 2005a; 2009). Several long-term time-series of abundance data of marine predators in the southern Indian Ocean have, for example, indicated that populations have decreased (or in some cases increased) during the last half of the 1900's, probably in response to changes in food availability (Weimerskirch et al. 2003). Long-term life history data of top predators such as seals and penguins are important given the increasing role that top predators are playing in the monitoring and management of marine ecosystems (Boyd et al. 2006), particularly as indicators of environmental change (e.g., Weimerskirch et al. 2003, Costa et al. 2010).

To be able to predict the responses of these populations to future conditions, the links between key fitness components (e.g., survival and fecundity) and the environment need to be understood. Individually based, long-term, longitudinal mark-recapture studies are ideal to identify the main demographic drivers of population dynamics, including processes that would not be obvious from abundance data alone (Lebreton et al. 1992, de Little et al. 2007). In nearly all mark-recapture studies a sub-sample of individuals, assumed to be representative of the whole population, is marked and subsequently recaptured or resighted during future encounters. The presence of unmarked individuals is therefore inherent to any mark-recapture study population. Unmarked individuals may originate from the studied population either because they were never marked, or because of marker loss. Alternatively, unmarked individuals may originate from other populations through the process of immigration. 
The origin of unmarked individuals within a mark-recapture study is important as their presence may (but does not necessarily) suggest violation(s) of some of the most fundamental closed population mark-recapture assumptions of analyses such as the Cormack-Jolly-Seber approach (Seber 1982; Lebreton et al. 1992). Where unmarked individuals originate from marker loss or immigration, more realistic open population models (Pollock 2000) that allow additions or removals representing immigration, emigration and marker loss, together with recruitment and mortality should be implemented to appropriately deal with assumption violations of simpler models. Knowledge of the origin of the unmarked population component is therefore vital if its potential impact on the entire population and parameter estimation is to be gauged.

The southern elephant seal Mirounga leonina is an abundant, wide-ranging marine predator with a circumpolar Southern Ocean distribution (Figure 1, McMahon et al. 2005a). Populations of southern elephant seals in the southern Indian Ocean (Kerguelen, Heard, Crozet, Marion and Prince Edward islands) and southern Pacific Ocean (Macquarie Island) declined by as much as $80 \%$ from 1950 to 2000 (McMahon et al. 2005a). In an attempt to understand the causal factors responsible for the decline at Marion Island (87\% decline from 1951 to 2004, McMahon et al. 2009), a long-term demographic study was established in 1983 to quantify the life-history parameters of this small, and at the time, declining population. The uninterrupted and ongoing mark-resight study is the only current long-term demographic study of elephant seals in the southern Indian Ocean.

Southern elephant seals have a predictable annual haulout cycle (Figure 2) characterised by well defined pelagic phases at sea between distinct "winter" (or mid-year), moult and breeding haulouts on land (Le Boeuf \& Laws 1994). The annual cycle of adult seals (see Methods for age class delineation) is often characterised by only two haulout phases: the breeding phase and the obligatory moult. Elephant seals are extreme capital breeders and females remain ashore for the entire lactation period of 21 to 23 days (Boyd 2000). The number of females ashore during the breeding haulout (September to November) follows a reliable normal distribution (Hindell and Burton 1988) with a peak on 15 October. During the austral summer, from November to March/April, all elephant seals older than the pups born in the preceding 
breeding season undergo an obligatory moult while hauled out ashore. Seals moult sequentially according to age and breeding experience (Hindell and Burton 1988; Slip and Burton 1999; Kirkman et al. 2003). During autumn and winter, seals (mostly juveniles) may return to land for a facultative mid-year or winter haulout (Kirkman et al. 2001; Field et al. 2005).

Elephant seals are considered to have high site fidelity, usually returning to the natal island to haul out (Nicholls 1970, McMahon et al. 1999, Hofmeyr 2000). However, site fidelity varies with age and sex classes and between different haulout phases. Adult females have particularly high levels of philopatry, especially in the breeding season. Notwithstanding the high levels of site fidelity, some degree of inter-island movement within the southern Indian Ocean is known to occur (Bester 1989; Guinet et al. 1992; Oosthuizen et al. 2009, Oosthuizen et al. 2011). Such movements are often part of foraging migrations of juvenile seals (van den Hoff 2001), but dispersal (emigration and immigration) also occurs (Oosthuizen et al. 2011). Although the full extent of inter-island movement is unknown, Marion Island appears to be an important winter resting and moult haulout site for juvenile seals from the Îles Crozet (Oosthuizen et al. 2011).

Elephant seal demographics have been widely studied using mark-recapture methodology at several locations throughout their range (e.g., McMahon et al. 2003, Pistorius et al. 2004). At Marion Island, the small population size (between 420 and 530 breeding females in the study period) permits individual marking (by flipper-tagging) of nearly all elephant seal pups born at the island. Under 3\% of pups born at Marion Island escaped tagging between 1986 and 2007 and this percentage decreased to $0.78 \%$ during the latter part $(2000-2007)$ of the study (Pistorius et al. 2011). This contrasts the majority of other mark-recapture studies (including elephant seal studies) where only a sub-sample of the population can be marked (e.g., Macquarie Island, McMahon et al. 1999; and Pensinsula Valdés, Pistorius et al. 2004). The tagging regime at Marion Island (25 years in 2008) has now extended longer than the known longevity of the species (20 and 23 years for males and females respectively - Hindell and Little 1988). Even so, a large proportion of seals hauling out at Marion Island are unmarked (untagged). Assuming that all pups born annually are marked (Pistorius et al. 2011), untagged 
seals observed at Marion Island could therefore originate from two sources namely tag-loss and migration/immigration.

Elephant seals are commonly marked by double-tagging in the hind flippers and tag-loss is an unavoidable component of long-term mark-resight programmes. Tagged seals that lose both flipper-tags over time and survive as untagged seals therefore become indistinguishable from seals that were never tagged. Tag-loss rates have been estimated at Marion Island (e.g., Oosthuizen et al. 2010) and elsewhere (e.g., McMahon and White 2009) to adjust mark-resight survival estimates for the loss of marked elephant seals from the population. At Marion Island, double tag-loss estimates are under $1 \%$ for seals aged less than five years. Tag loss rates increase as seals age and double tag-loss cumulates to $11.9 \%$ (females) and $18.4 \%$ (males) during the lifetime of seals (Oosthuizen et al. 2010). However, tag-loss analyses assume independent tag loss (i.e., the probability of losing the second tag is not dependent on the probability of losing the first tag) - a likely unjustified assumption (McMahon and White 2009). Violation of this assumption will lead to underestimated tag-loss rates, and a larger proportion of untagged seals.

Alternatively, untagged seals observed at Marion Island may be migrants (non-breeding) or immigrants (part of the breeding population), having dispersed from other elephant seal populations within the southern Indian Ocean, or even further afield. Dispersal rates (immigration and emigration) are difficult to measure (Nathan 2001) and robust dispersal rate estimates are lacking for Marion Island.

Tag-loss and migration/immigration thus both contribute unmarked individuals to the Marion Island population. The two mechanisms are, however, predicted to add individuals to different age classes of the population. Tag-loss is expected to add unmarked individuals mainly to adult age categories (Oosthuizen et al. 2010) and therefore, if tag-loss is the foremost source of untagged seals at Marion Island, juvenile age classes should have the greatest proportion of tagged individuals. Conversely, dispersal is predicted to augment juvenile numbers more so than adult numbers and thus we expect unmarked seals to be most prevalent during nonbreeding haulouts where juveniles predominate. 
In this paper we describe the composition of the southern elephant seal population at Marion Island in terms of the relative numbers of marked (tagged) and unmarked (untagged) seals that haul out to breed, moult and winter. Our main aim is to identify patterns in the occurrence of marked and unmarked individuals that will allude to the possible origin of the untagged component of the population. We achieve this by comparing the relative numbers of marked and unmarked seals per age and sex class at monthly and annual time scales. Additionally, we illustrate differential site usage between tagged and untagged seals that may be influenced by the presence or absence of site fidelity to a local birth site by tagged and untagged seals respectively. The results of this study indicate the need for a holistic and integrative view of southern elephant seal populations within the southern Indian Ocean.

\section{Methods}

\section{Study area}

The Prince Edward Islands (PEIs) comprise two islands, Marion Island and Prince Edward Island (19 km to the northeast of Marion Island). Approximately 540 and 130 elephant seal females currently breed at Marion and Prince Edward Island respectively. Îles Crozet, some $1000 \mathrm{~km}$ distant is the nearest island group to the PEIs and approximately 550 elephant seal females breed there (Guinet et al. 1999). The largest populations of southern elephant seals within this sector of the Southern Ocean occur at Îles Kerguelen and Heard Island (40 000 [Authier et al. 2011] and 18000 [Slip and Burton 1999] breeding females respectively) (Figure $1)$.

\section{Field methods}

Since 1983, virtually all recently weaned southern elephant seal pups born at Marion Island were sexed and double tagged in the interdigital webbing of the hind flippers with identical, uniquely numbered, colour-coded plastic Dal 008 Jumbotags ${ }^{\circledR}$ (Dalton Supplies Ltd., Henleyon-Thames, United Kingdom) (de Bruyn et al. 2008). In conjunction with tagging, resights of elephant seals were made on a regular 7- or 10-day cycle including all beaches along a $51.9 \mathrm{~km}$ coastline where elephant seals regularly haul out (Figure 1). Beaches on the west coast where elephant seals infrequently haul out were visited once a month. Annual encounter (resight) probabilities of marked seals are high (mean approximately 0.75, McMahon et al. 2003). All 
haulout sites around the island are identified by numerical codes (MM001 - MM068). For brevity, these are given as " 1 " to " 68 " in this manuscript.

For every tagged seal resighted, the date, locality, tag colour combination and three-digit number, number of tags remaining and the sex of the seal (if identified) were recorded. Untagged seals were counted and grouped into discrete age class categories based on morphological characters and visual comparison to known aged seals. Age class categories are: pup (suckling and weaned pups); under-yearling (age $<1$ year, excluding pups); yearling (age 1 to $<2$ year); subadult (age 2 to $<3$ or $<4$ year for females [depending on breeding history] and age 2 to $<6$ for males); adult female (age $\geq 4$ [or $\geq 3$ if giving birth at age 3]); adult male (age $\geq 6$ year). Collectively, under-yearling, yearling and subadult age classes are referred to as "juveniles". Juvenile age classes comprise males and females as the sex of an individual is not always discernible.

During regular censuses (described above) from May 1997 to April 2009, "site-census data" were recorded at every beach (site) where elephant seals were observed. Site-census data comprise of (1) the number of seals recorded in each age class $(n=135820),(2)$ the number of these seals inspected for the presence of tags $(n=128$ 302) and (3) the number of seals bearing "Marion Island" tags $(\mathrm{n}=48$ 555). Sample sizes refer to the total number of seals recorded in each category and were obtained from 13128 distinct site census records (particular date and site). Unweaned and weaned pups present at the island during the post-weaning period do not form part of site-census data and are excluded from all analyses presented here. Individuals from the youngest age class incorporated into site-census data (under-yearlings) must therefore have made at least one foraging trip to sea.

\section{Analyses}

Although it is possible to determine the number of individual untagged seals present at Marion Island during any single census, the fact that they are untagged (i.e. unidentifiable) precludes exact calculation of seasonal or annual numbers of individuals. Furthermore, seal numbers fluctuate seasonally according to the haulout cycle. Therefore, to determine the relative abundance of the untagged population component, we compared the number of untagged seals 
to the number of Marion Island tagged seals. This estimate, defined as the "tag-ratio", is expressed as the proportion of tagged individuals (i.e. the number of tagged seals present divided by the number of seals inspected for tags). A low tag-ratio $(<0.5)$ is therefore indicative of a surplus of untagged individuals. Seals not inspected for tags on any particular occasion were excluded from analyses (about 5\% of seals encountered on any particular census; Mammal Research Institute unpublished data, 1997 - 2009).

Temporal variation in tag-ratios was considered at monthly and annual time scales. Monthly comparisons allow detailed partitioning of the annual haulout cycle (see Introduction, Figure 2). Annual comparisons $(n=11)$ were made between "expedition years", from beginning $\operatorname{May}_{(t)}$ to end April $_{(t+1)}$. Site-census data were not reliably collected from May 2002 to April 2003 and this year was excluded from all analyses. Additionally, the entire adult female and partial adult male components of 2001 and the entire adult male component of 2004 were excluded due to incongruous data collection for these age classes in the specific years. Five age class categories were considered: adult males, adult females and mixed-sex groups for subadults, yearlings and under-yearlings.

We initially fitted a generalized linear model (GLM, McCullagh and Nelder 1989) with a binomial error distribution and a logit link function (Venables and Ripley 2002) using programme R (R Development Core Team 2004). Tag-ratio was modeled as the dependent variable with the factors year, month, age class and all second order interactions as explanatory variables. In binomial GLMs, the deviance is assumed to follow a chi-square distribution, with the residual deviance expected to be approximately equal to the residual degrees of freedom. As we found evidence of overdispersion in initial modeling using the binomial family argument (residual deviance greater than residual degrees of freedom, dispersion parameter $=$ 3.04), we refitted the model using quasi-likelihood (family = quasibinomial) that alleviates the assumption that the binomial errors follow a chi-square distribution (Venables and Ripley 2002). Neither the Durbin-Watson test statistic (2.108) nor inspection of the sample autocorrelation function (ACF) plot suggested that residuals were autocorrelated. The significance of terms in the model was assessed using non-sequential (type II) analyses of deviance $\mathrm{F}$ tests with the significance level set as $\mathrm{p}<0.05$ (Hardy 2002; Crawley 2007). 
Site usage of tagged and untagged seals was compared for all sites where in total, more than 100 seals were inspected for tags between May 1997 and April $2009(n=43)$. During this period, the overall mean tag-ratio across all sites was 0.378 (48 555 sightings of tagged seals from 128302 seals inspected for tags). To examine whether certain sites had higher or lower proportions of tagged individuals than the mean across all sites, we applied a two-tailed binomial test in $\mathrm{R}$ with the hypothesized probability of success (p) set to 0.378 . This model tests the null-hypothesis that the tag-ratio for a specific site does not differ from the mean $(\mathrm{p}=$ $0.378)$ and the alternative hypothesis that tag-ratios are above or below the mean $(\mathrm{p} \neq 0.378)$. We used 95\% confidence intervals (CI) to categorise sites as having lower than expected tagratios (upper $\mathrm{CI}<0.378$ ) or higher than expected tag-ratios (lower $\mathrm{CI}>0.378$ ). Sites where the CI contains 0.378 exhibit no evidence to reject the null hypothesis. To avoid increasing incorrect rejection of the null hypothesis (Type I error) due to multiple comparisons between 43 sites, confidence intervals were adjusted using the Dunn-Šidák correction (Sokal and Rohlf $1995)$ to ensure a level of statistical significance equivalent to $p=0.05$ (95\% confidence intervals). To explain the observed difference in tag-ratios between sites, we (1) related tagratios to the 'popularity' of a site as indexed by the total number of seals observed at each site during the study period and (2) compared the age class specific utilization of sites with tagratios above and below the mean respectively.

\section{Results}

Counts of seals (marked and unmarked combined) fluctuated predictably throughout the study period as a function of the cyclic haulout pattern of elephant seals. During the austral winter, juvenile age categories occurred almost exclusively. Numbers of adult seals increased during the breeding season (peaking in October), followed by an overall peak in numbers during the annual moult. Numbers of moulting yearling and subadult seals were the highest in December, those of adult females in January, and adult males in March (Figure 2).

\section{Effect of age class and time on tag-ratios}

All first and second order terms included in the starting GLM model were highly significant ( $p$ $<0.001)$ and as a consequence we did not simplify the starting model any further. Monthly 
differences in tag-ratios $(\mathrm{F}=41.12, \mathrm{df}=11, \mathrm{p}<0.001)$ largely correlated to the cyclic haulout pattern of elephant seals (Figure 3). The highest proportion of tagged animals was present during the breeding season (September and October) with a maximum tag-ratio during the peak adult female haulout in October when, on average, almost $50 \%$ of the population in attendance have tags. Tag-ratios declined after the breeding season (November) associated with the onset of moult, which lasts until January/February (adult females) or March/April (adult males). During the moult period tag-ratios increased from 0.40 (mean value, November) to 0.43 (January), then decreased to 0.35 and 0.38 in February and March respectively. Proportionally, the fewest tagged individuals (tag-ratio $<0.3$ ) hauled out during the austral autumn and winter (April to August). Tag-ratios reached a minimum (mean $=0.22$ ) in August, immediately prior to the onset of the breeding season. Monthly tag-ratios varied between years (Figure 3, F = $1.69, \mathrm{df}=110, \mathrm{p}<0.001)$, but this variation did not obscure the relationship between seasonal haulout patterns and tag-ratios.

Age class had a strong influence on tag-ratios $(\mathrm{F}=249.60, \mathrm{df}=4, \mathrm{p}<0.001)$. Adult males $(0.43)$ and adult females in particular (0.49), recorded the greatest proportions of tagged seals relative to the number of untagged seals; yet these ratios were still below 0.5 , indicating that more than half of all adult seals resighted were untagged. Juvenile age categories had lower tag-ratios that declined with decreasing age: subadults $(0.36)$, yearlings $(0.32)$ and underyearlings (0.26) (Figure 4). Tag-ratios varied for age classes within a year depending on the haulout phase (delineated by month; age:month interaction $\mathrm{F}=11.59, \mathrm{df}=44, \mathrm{p}<0.001$ ).

Tag-ratios decreased from 1997 to $2009(\mathrm{~F}=14.04, \mathrm{df}=10, \mathrm{p}<0.001)$ and model fit was improved by separating the trend in decrease for different age classes $(\mathrm{F}=3.50, \mathrm{df}=38, \mathrm{p}<$ $0.001)$. Adult male tag-ratios varied more than other age classes between years $(\mathrm{SD}=0.54$, mean SD for other age classes $=0.45)$, and did not appear to decline systematically $(-0.0029$ year $\left.^{-1}\right)$. The slope of the regression line of the fitted probabilities predicted by the GLM was negative for all other groups: adult females (-0.0064), subadults (-0.0063), yearlings (-0.047) and under-yearlings (-0.0065) (Figure 5). 
Site usage by tagged and untagged seals

Sites on the north-eastern aspect of Marion Island $(n=9)$, from Goney Bay in the north (53) to Ship's Cove in the south (65), usually had higher proportions of tagged seals present (Figure 6). Two other locations on the island's southern aspect, namely Kildalkey Bay (20) and Goodhope Bay (26), also had tag-ratios above the mean. Sites where untagged seals occurred more than expected (tag-ratio upper $\mathrm{CI}<0.378, n=14$ ) and those with tag-ratios similar to the mean $(n=18)$ were interspersed along the east coast (Figure 6).

The relative abundance of tagged and untagged seals was not explained by the total number of seals that occupied a specific site over time (linear model, $p=0.40, R^{2}=0.017$, Figure 7a). More importantly, the age class specific utilization of different sites influenced tag-ratios. Sites where tagged seals occurred more (tag-ratio lower CI > 0.378) was utilized by greater proportions of adult seals relative to juvenile seals, whereas sites with comparatively few tagged seals (tag-ratio $\mathrm{CI} \leq 0.378$ ) were utilized by greater proportions of juvenile seals (Figure $7 b)$.

\section{Discussion}

The origin and significance of unmarked individuals in mark-recapture studies has received little attention even though they could provide valuable information on population dynamics such as immigration rates (e.g., Coulson and Coulson 2008) which can be a key component of the local population dynamics. Using a long term mark-resight study of southern elephant seals where all individuals born to the local population are marked, we aimed to attribute the presence of large numbers of unmarked seals to one of two possible origins: marker loss or immigration. Although both these mechanisms augment the unmarked population component, our results suggest that immigration (temporary or permanent) is an especially important source of untagged seals. Whereas tag-loss cumulates with age (Oosthuizen et al. 2010) and is thus expected to add unmarked individuals to mainly adult age categories, unmarked migrants/immigrants are expected to be primarily juveniles (Oosthuizen et al. 2011). Our results indicated that the overall relative abundance of untagged seals (represented by tagratios) was high, especially during the periods when juvenile seals haul out. 
Site fidelity and inter-island movement of untagged seals

Unambiguous evidence indicates that elephant seals, like many other pinnipeds (e.g., grey seals Halichoerus grypus, Pomeroy et al. 1994, Australian sea lion Neophoca cinerea, Campbell et al. 2008) show high fidelity to their natal beaches, i.e., most individuals are philopatric. At Peninsula Valdés, $86 \%$ of elephant seal females return to within $3 \mathrm{~km}$ of their birth site (Lewis et al. 2006) and at Macquarie Island $77 \%$ of females return to within $4 \mathrm{~km}$ of their birth site (Nicholls 1970). Similar high site fidelity occurs at Marion Island, where approximately 51\% of females return to within $5 \mathrm{~km}$ of their birth site (Hofmeyr 2000). Considering such high site fidelity, the occurrence of a large number of untagged seals (outnumbering tagged seals) at Marion Island appears contradictory. Fidelity to the natal island is, however, lower for juveniles and for adults during non-breeding haulouts (Hofmeyr 2000) and some degree of inter-island movement does occur between Marion Island and neighbouring Prince Edward Island (Oosthuizen et al. 2009), Îles Crozet and Îles Kerguelen (Bester 1988, 1989, Guinet et al. 1992, Oosthuizen et al. 2011). But, as a consequence of inadequate observer effort both spatially and temporally, movement-rates amongst these islands remain difficult to quantify.

Annually, more than $50 \%$ of surviving under-yearlings born and tagged at Marion Island and more than $60 \%$ of surviving yearlings (of both sexes) haul out to winter at the natal site (Kirkman et al. 2001). Juvenile males aged two to four continue to haul out in high proportions during winter (Kirkman et al. 2001), but even so, untagged seals outnumber tagged seals three to one during this phase. Marion Island is an important winter haulout site for untagged seals from the Îles Crozet, but possibly also Îles Kerguelen (Oosthuizen et al. 2011). The high relative abundance of untagged seals during winter suggests that these seals forage in the region of Marion Island (rather than near their natal island).

The sequential moulting of juveniles, followed by adult females and then adult males during the moult haulout (November - March) coincided with a change in tag-ratios. Relatively low tag-ratios in November (during the principal juvenile moult phase) increased in December, and reached a peak during January (predominantly adult female moult haulout), indicating that more untagged juvenile than adult female seals moulted at Marion Island, relative to the tagged population. Tag-ratios during the adult male moult haulout (February to March) were the 
lowest recorded during the moult season, but were not unexpected as some adult males are known to repeatedly visit alternative non-breeding haulout sites during the moult. A number of males from Heard and Macquarie islands moult at the Vestfold Hills and Windmill Islands in Antarctica, for example (Burton 1985; Bester 1988; van den Hoff et al. 2003), whereas males breeding on Îles Kerguelen have moulted at Marion Island (Oosthuizen et al. 2011).

Even though the highest tag-ratios were recorded for breeding females, approximately half of all breeding females are untagged. A proportion of the large number of migrant juvenile seals at Marion Island during non-breeding haulouts is expected to permanently immigrate to the breeding population (suggested by the proportion of untagged breeding females and observations of seals tagged at Îles Crozet breeding at Marion Island [Oosthuizen et al. 2011]). Breeding dispersal of elephant seals between Marion Island and other islands is generally assumed to have negligible influence on population parameters (Pistorius et al. 1999; but see Bradshaw et al. 2002) or population trends (McMahon et al. 2009) even though the substantial positive consequence of immigration on population growth has been demonstrated through population modeling (McMahon et al. 2005b). Given the importance that immigration may have on population structure and growth rate, the ability to identify immigrants and therefore the capability to distinguish between local births and immigration is critical. However, in contrast to the current study, most mark-recapture studies are ill-suited to identify unmarked individuals as immigrants, simply because not all individuals in the local population are marked. One example where immigrants could be distinguished from locally born offspring is in specific black-legged kittiwake Rissa tridactyla colonies where all young produced in the colony were ringed over an extended period (up to 36 successive years, Coulson and Coulson 2008). Philopatry appeared to be lower than generally assumed for these colonial seabirds when the number of philopatric recruits in a colony was related to the total number of new recruits to that colony (Coulson and Coulson 2008).

From 1997 to 2009, the number of untagged seals recorded at Marion Island increased relative to the number of tagged seals, probably as a consequence of both increased immigration and tag-loss. The decrease in tag-ratios may be associated with the stabilization of declining elephant seal populations at Îles Kerguelen (stable since 1987) and Îles Crozet (stable since 
1990, Guinet et al. 1999). Stable (to increasing) source populations at Îles Kerguelen and Îles Crozet may result in greater migration rates to Marion Island if positive density-dependent emigration is present (Matthysen 2005). The recent inflexion in population growth of elephant seals at Marion Island from decrease to increase (McMahon et al. 2009) could perhaps be attributed to an increase in immigrant seals accompanied by improved survivorship of Marion Island seals (de Bruyn 2009). However, the decrease in tag-ratios over time also fits with a change in the tagging protocol at Marion Island. Since 2000, elephant seal pups were marked by tagging in the upper, outer interdigital webbing of the hind flippers (to improve tag resighting), rather than the inner interdigital webbing of the hind flippers (1983 - 1999). The new tag site appears to have higher tag-loss rates (Oosthuizen et al. 2010) and will consequently result in more native untagged seals.

Our results suggest that the local populations in the southern Indian Ocean interact via individuals moving among island-populations. This may also be the case for elephant seal populations within other geographical provinces, such as the South Georgia stock. There, the sub-population at South Georgia (over 100000 females, McMahon et al. 2005a) may significantly contribute individuals to elephant seal populations at, for example, the South Shetland and Falkland Islands, through emigration. The validity of this hypothesis, however, remains untested.

\section{Site usage by tagged and untagged seals}

Significantly more tagged than untagged seals hauled out on the northeastern coastline and at two sites on the south coast. Although tag-ratios were unrelated to the popularity of a site (measured as the total number of seals that haul out), higher tag-ratios (more tagged individuals) were positively coupled to higher proportions of adult seals relative to juvenile seals that utilize specific sites. The distribution of the largest harems (number of female breeders, and consequently numbers of tagged pups added to the study population per annum per site) is not regular along the coastline, but with two exceptions (sites 7 and 18, Figure 6)

includes all sites with tag-ratios above the mean. Local site fidelity (returning to the same beach) maintained the difference in numbers of tagged seals on different sections of the coastline for all age classes. Untagged seals appear to be distributed evenly amongst sites 
rather than occurring in greater numbers at large breeding sites - as this would have had a homogenising effect on tag-ratios between sites. Although immigrant seals lack fidelity to a birth site (at Marion Island), they may be philopatric to sites where they hauled out previously as juveniles.

\section{Drawing inference from unmarked individuals}

The current analysis was facilitated by the long-term southern elephant seal mark-resight programme at Marion Island. Migrant seals appear to be abundant at the site, but as untagged migrant seals clearly do not form part of the marked population, their presence will not result in spurious survival rates estimated from the marked population. Projected population growth derived from mark-resight survival and fecundity rates may, however, not correlate to observed total population trends, as immigrant seals are an additional source of seals, including breeders. The difference in population growth rates estimated from counts of individuals over multiple sampling periods compared with population growth estimates from age-structured projection matrix models (Peery et al. 2006) may therefore be used to estimate dispersal rates.

Where possible, researchers utilizing mark-recapture methodology should also collect information on the unmarked component of their study population as such data (e.g., counts, birth rates) may, in combination with mark-recapture data, improve biological conclusions. Integrated data analysis, for example, allows different data sets to be analysed together to better disentangle the confounding effects of dispersal and marker loss on mortality of marked individuals (e.g., Reynolds et al. 2009). It may rarely be possible to assign individuals as immigrants simply because they are unmarked, but even so, it may be possible to estimate immigration rates even without directly observing individuals dispersing from one population to another. Population genetic approaches (assignment methods, Manel et al. 2005) may assist to improve estimates of local reproduction and immigration. Lastly, temporal symmetry markrecapture models (Pradel 1996) can be used to estimate the rate of immigration by subtracting local recruitment (reproduction only) from total recruitment (reproduction plus immigration). 


\section{Acknowledgements}

The authors thank the many devoted personnel who collected long-term mark-recapture data on elephant seals at Marion Island. Logistical support and research permits were provided by the South African Department of Environmental Affairs within the South African National Antarctic Programme. The Department of Science and Technology, through the National Research Foundation (NRF), provided financial support. WCO received financial support from a NRF Grantholder-linked bursary within the project "Conservation of Seabirds, Shorebirds and Seals" led by L. Underhill of the Animal Demography Unit, Department of Zoology, University of Cape Town. The project has ethics clearance from the Animal Use and Care Committee (AUCC 040827-024) of the Faculty of Veterinary Science, University of Pretoria. We gratefully acknowledge the input of I.C. Field, R.R. Reisinger, M. Nevoux, an associate editor and three anonymous reviewers, whose comments greatly improved the manuscript.

\section{References}

Authier, M., Delord, K. \& Guinet, C. (2011) Population trends of female Elephant Seals breeding on the Courbet Peninsula, îles Kerguelen. Polar Biol. 34, 319-328.

Bester, M. N. (1988) Marking and monitoring studies of the Kerguelen stock of southern elephant seals, Mirounga leonina, and their bearing on biological research in the Vestfold Hills. Hydrobiologia 165, 269-277.

Bester, M. N. (1989) Movements of southern elephant seals and Subantarctic fur seals in relation to Marion Island. Mar. Mamm. Sci. 5, 257-265.

Boyd, I. L., Wanless, S. \& Camphuysen, C. J. (Eds) (2006) Top predators in marine ecosystems. Their role in monitoring and management. Cambridge University Press, Cambridge.

Bradshaw, C. J. A., McMahon, C. R., Hindell, M. A., Pistorius, P. A. \& Bester, M. N. (2002) Do southern elephant seals show density dependence in fecundity? Polar Biol. 25, 650655.

Burton, H. R. (1985) Tagging studies of male southern elephant seals (Mirounga leonina L.) in the Vestfold Hills area, Antarctica, and some aspects of their behaviour. In: Sea mammals in south latitudes: Proceedings of a Symposium of the 52nd ANZAAS Congress. (Eds. J. K. Ling and M. M. Bryden.) pp. 19-30. South Australian Museum, Adelaide. 
Campbell, R. A., Gales, N. J., Lento, G. M. \& Baker, C. S. (2008) Islands in the sea: extreme female natal site fidelity in the Australian sea lion, Neophoca cinerea Biol Lett 4, 139142.

Caughley, G. (1994) Directions in conservation biology. J. Anim. Ecol. 63, 215-244.

Costa, D. P., Huckstadt, L. A., Crocker, D. E., McDonald, B. I., Goebel, M. E. \& Fedak, M. A. (2010) Approaches to studying climatic change and its role on the habitat selection of Antarctic pinnipeds. Integr. Comp. Biol. 50, 1018-1030.

Coulson, J. C. \& Coulson, B. A. (2008) Measuring immigration and philopatry in seabirds; recruitment to Black-legged Kittiwake colonies. Ibis 150, 288-299.

Crawley, M. J. (Ed.) (2007) The R book. John Wiley \& Sons, Ltd, Chichester.

de Bruyn, P. J. N. (2009) Life history studies of the southern elephant seal population at Marion Island. $\mathrm{PhD}$ thesis, University of Pretoria, Pretoria.

de Bruyn, P. J. N., Tosh, C. A., Oosthuizen, W. C., Phalanndwa, M. V. \& Bester M. N. (2008) Temporary marking of unweaned southern elephant seal (Mirounga leonina L.) pups. S. Afr. J. Wildl. Res. 38, 133-137.

de Little, S. C., Bradshaw, C. J. A., McMahon, C. R. \& Hindell, M. A. (2007) Complex interplay between intrinsic and extrinsic drivers of long-term survival trends in southern elephant seals. BMC Ecology 7, doi:10.1186/1472-6785-7-3.

Fabiani, A., Hoelzel, A. R., Galimberti, F. \& Muelbert, M. M. C. (2003) Long-range paternal gene flow in the southern elephant seal. Science 299, 676.

Field, I. C., Bradshaw, C. J. A., Burton, H. R., Sumner, M. D. \& Hindell, M. A. (2005) Resource partitioning through oceanic segregation of foraging juvenile southern elephant seals (Mirounga leonina). Oecologia 142, 127-135.

Guinet, C., Jouventin, P. \& Weimerskirch, H. (1992) Population changes, movements of southern elephant seals on Crozet and Kerguelen Archipelagos in the last decades. Polar Biol. 12, 349-356.

Guinet, C., Jouventin, P. \& Weimerskirch, H. (1999) Recent population change of the southern elephant seal at Îles Crozet and Îles Kerguelen: the end of the decrease? Antarct. Sci. 11, 193-197.

Hardy, I. C. W. (Ed.) (2002) Sex Ratios: Concepts and Research Methods. Cambridge University Press: Cambridge. 
Hofmeyr, G. J. G. (2000) Dispersal and dispersion in the southern elephant seal Mirounga leonina at Marion Island. MSc Dissertation, University of Pretoria, Pretoria.

Hindell, M. A. \& Burton, H. R. (1988) Seasonal haul-out patterns of the southern elephant seal (Mirounga leonina L.), at Macquarie Island. J. Mammal. 69, 81-88.

Hindell, M. A. \& Little, G. J. (1988) Longevity, fertility and philopatry of two female southern elephant seals (Mirounga leonina) at Macquarie Island. Mar. Mamm. Sci. 4, 168-171.

Kirkman, S. P., Bester, M. N., Pistorius, P. A., Hofmeyr, G. J. G., Owen, R. \& Mecenero, S. (2001) Participation in the winter haulout by southern elephant seals (Mirounga leonina). Antarct. Sci. 13, 380-384.

Kirkman, S. P., Bester, M. N., Pistorius, P. A., Hofmeyr, G. J. G., Jonker, F. C. Owen, R. \& Strydom, N. (2003) Variation in the timing of moult in southern elephant seals at Marion Island. S. Afr. J. Wildl. Res. 33, 79-84.

Kirkman, S. P., Bester, M. N., Hofmeyr, G. J. G., Jonker, F. C., Pistorius, P. A., Owen, R. \& Strydom, N. (2004) Variation in the timing of the breeding haulout of female southern elephant seals at Marion Island. Aust. J. Zool. 52, 379-388.

Le Boeuf, B. J. \& Laws, R. M. (1994) Elephant seals: an introduction to the genus. In: Elephant seals: population ecology, behavior and physiology (Eds B. J. Le Boeuf, and R. M. Laws.) pp.1-26. University of California Press, Berkeley.

Lebreton, J -D., Burnham, K. P., Clobert, J. \& Anderson, D. R. (1992) Modeling survival and testing biological hypotheses using marked animals: a unified approach with case studies. Ecol. Monogr. 62, 67-118.

Lewis, M., Campagna, C. \& Quintana, F. (1996) Site fidelity and dispersion of southern elephant seals from Patagonia. Mar. Mamm. Sci. 12, 138-147.

Manel, S., Gaggiotti, O. E. \& Waples, R. S. (2005) Assignment methods: matching biological questions with appropriate techniques. Trends Ecol. Evol. 20, 136-142.

Matthysen, E. (2005) Density-dependent dispersal in birds and mammals. Ecography 28, 403416

McCullagh, P. \& Nelder, J. A. (1989) Generalized Linear Models. Chapman \& Hall, London.

McMahon, C. R. \& White, G. C. (2009) Tag loss probabilities are not independent: Assessing and quantifying the assumption of independent tag transition probabilities from direct observations. J. Exp. Mar. Biol. Ecol. 372, 36-42. 
McMahon, C. R., Burton, H. R. \& Bester, M. N. (1999) First-year survival of southern elephant seals, Mirounga leonina, at sub-Antarctic Macquarie Island. Polar Biol. 21, 279284.

McMahon, C. R., Burton, H. R. \& Bester, M. N. (2003) A demographic comparison of two southern elephant seal populations. J. Anim. Ecol. 72, 61-74.

McMahon, C. R., Bester M. N., Burton H. R., Hindell M. A. \& Bradshaw, C. J. A. (2005a) Population status, trends and a re-examination of the hypotheses explaining the recent declines of the southern elephant seal Mirounga leonina. Mammal Rev. 35, 82-100.

McMahon, C. R., Hindell, M. A., Burton, H. R. \& Bester, M. N. (2005b) Comparison of southern elephant seal populations, and observations of a population on a demographic knife-edge. Mar. Ecol. Prog. Ser. 288, 273-283.

McMahon, C. R., Bester, M. N., Hindell, M. A., Brook, B. W. \& Bradshaw, C. J. A. (2009) Shifting trends: detecting environmentally mediated regulation in long-lived marine vertebrates using time-series data. Oecologia 159, 69-82.

Nathan, R. (2001) The challenges of studying dispersal. Trends Ecol. Evol. 16, 481-483.

Nicholls, D. G. (1970) Dispersal and dispersion in relation to the birthsite of the southern elephant seal, Mirounga leonina (L.), of Macquarie Island. Mammalia 34, 598-616.

Oosthuizen, W. C., Bester, M. N., de Bruyn, P. J. N. \& Hofmeyr, G. J. G. (2009) Intraarchipelago moult dispersion of southern elephant seals at the Prince Edward Islands, southern Indian Ocean. Afr. J. Mar. Sci. 31, 457-462.

Oosthuizen, W. C., de Bruyn, P. J. N., Bester, M. N. \& Girondot, M. (2010) Cohort and tagsite specific tag-loss rates in mark-recapture studies: a southern elephant seal cautionary case. Mar. Mamm. Sci. 26, 350-369.

Oosthuizen, W. C., Bester, M. N., Tosh, C. A., Guinet, C., Besson, D. \& de Bruyn, P.J.N. 2011. Dispersal and dispersion of southern elephant seals in the Kerguelen Province, Southern Ocean. Antarct. Sci. In press.

Peery, M. Z., Becker, B. H. \& Beissinger, S. R. (2006) Combining demographic and countbased approaches to identify source-sink dynamics of a threatened seabird. Ecol. Appl. 16, 1516-1528. 
Pistorius, P. A., Bester, M. N. \& Kirkman, S. P. (1999) Survivorship of a declining population of southern elephant seals, Mirounga leonina, in relation to age, sex, and cohort. Oecologia 121, 201-211.

Pistorius, P. A., Bester, M. N., Lewis, M. N., Taylor, F. E., Campagna, C. \& Kirkman, S. P. (2004) Adult female survival, population trend, and the implications of early primiparity in a capital breeder, the southern elephant seal (Mirounga leonina). J. Zool. (Lond.) 263, 107-119.

Pistorius P. A., de Bruyn P. J. N. \& Bester M. N. (2011) Population dynamics of southern elephant seals: a synthesis of three decades of demographic research at Marion Island. Afr. J. Mar. Sci. In press.

Pollock, K. H. (2000) Capture-recapture models. J. Am. Stat. Assoc. 95, 293-296.

Pomeroy, P. P., Anderson, S. S., Twiss, S. D. \& McConnell, B. J. (1994) Dispersion and site fidelity of breeding female grey seals (Halichoerus grypus) on North Rona, Scotland. $J$. Zool. (Lond.) 233, 429-447.

Pradel, R. (1996) Utilization of capture-mark-recapture for the study of recruitment and population growth rate. Biometrics 52, 371-377.

R Development Core Team. (2004) R: a Language and Environment for Statistical Computing. Royal Foundation for Statistical Computing, Vienna, Austria. ISBN 3-900051-07-0, http://www.R-project.org.

Roberts, C. M. \& Hawkins, J. P. (1999) Extinction risk in the sea. Trends Ecol. Evol. 14, 241246.

Reynolds, T. J., King, R., Harwood, J., Frederiksen, M., Harris, M. P. \& Wanless, S. (2009) Integrated data analysis in the presence of emigration and mark loss. J. Agric. Biol. Environ. Stat. 14, 411-431.

Seber, G. A. F. (1982) The estimation of animal abundance and related parameters $\left(2^{\text {nd }}\right.$ Edition). Charles Griffin \& Company Ltd, London.

Slip, D. J. \& Burton, H. R. (1999) Population status and seasonal haulout patterns of the southern elephant seal (Mirounga leonina) at Heard Island. Antarct. Sci. 11, 38-47.

Sokal, R. \& Rohlf, F. (1995) Biometry. WW Freeman, San Fransisco. 
van den Hoff, J. (2001) Dispersal of southern elephant seals (Mirounga leonina) marked at Macquarie Island. Wildl. Res. 28, 413-418.

van den Hoff, J., Davies, R. \& Burton, H. (2003) Origins, age composition and change in numbers of moulting southern elephant seals (Mirounga leonina) in the Windmill Islands, Vincennes Bay, east Antarctica, 1988 - 2001. Wildl. Res. 30, 275-208.

Venables, W. N. \& Ripley, B. D. (2002) Modern Applied Statistics with $S$ (4 ${ }^{\text {th }}$ Edition). Springer, New York.

Weimerskirch, H., Inchausti, P., Guinet, C. \& Barbraud, C. (2003) Trends in bird and seal populations as indicators of a system shift in the Southern Ocean. Antarct. Sci. 15, 249256. 


\section{List of Figures}

Figure 1. The distribution of the major breeding populations of southern elephant seal in the Southern Ocean (squares) and the location of elephant seal sub-populations within the southern Indian Ocean. Inset: Marion Island $\left(300 \mathrm{~km}^{2}\right)$. The main study area (see Methods) is from Storm Petrel Bay in the north, clockwise to Goodhope Bay in the south.

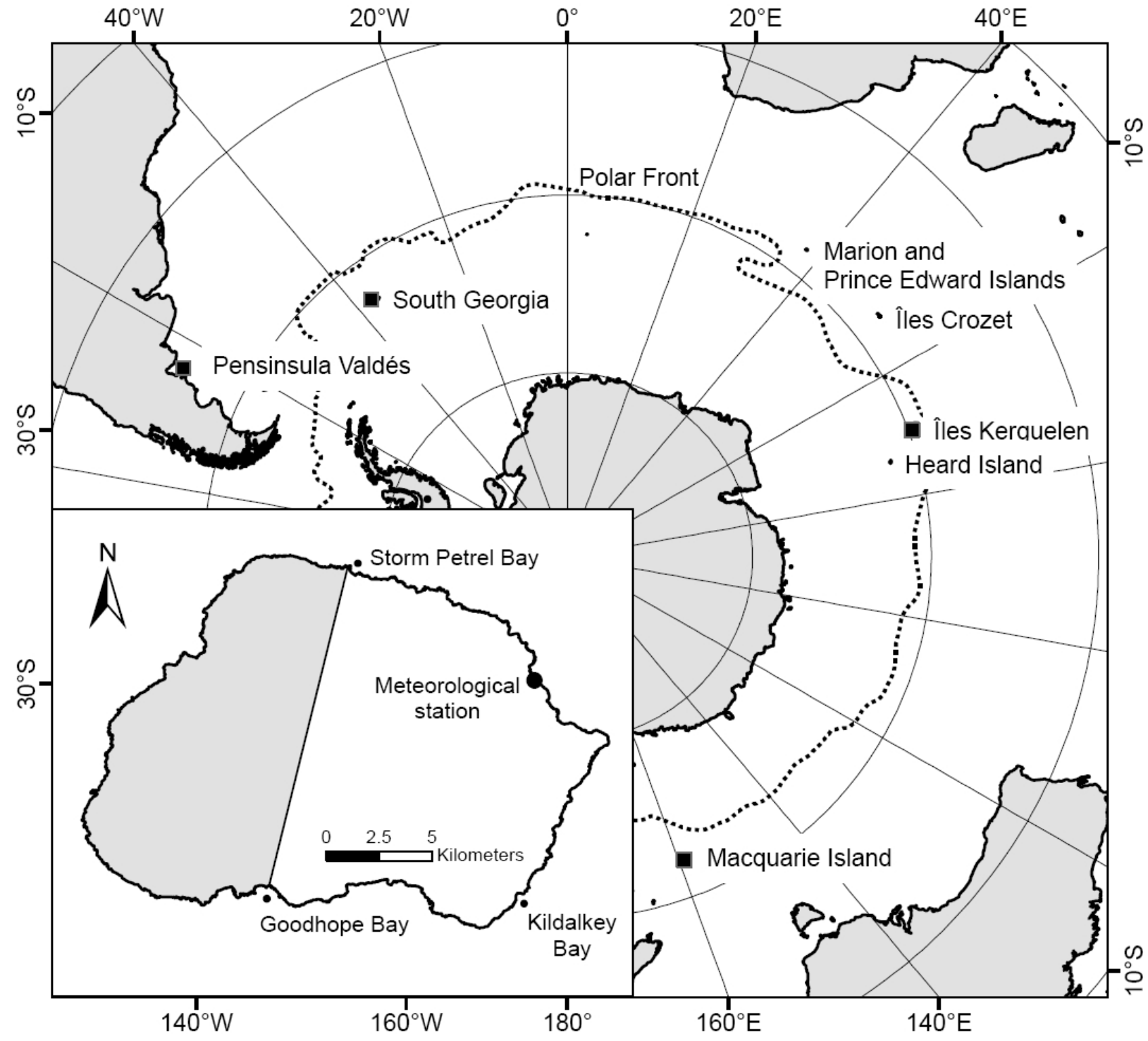


Figure 2. A. Number of southern elephant seals resighted while hauled out over a three year period at Marion Island to illustrate the regular seasonal haulout pattern. The annual haulout cycle can be divided into three principal phases namely: Winter (W, March - August), Breeding (B, August-November) and Moult (M, November-April). The y-axis corresponds to the total number of seals recorded during regular censuses (solid line) and the number of tagged seals observed (dotted line). Multiple resights of the same individual during a single haulout period are included. The letters $W, B$ and $M$ denote peaks in the winter, breeding and moult haulout respectively. B. The annual haulout cycle for different age classes over a 12 year period (1997 - 2009) at Marion Island.
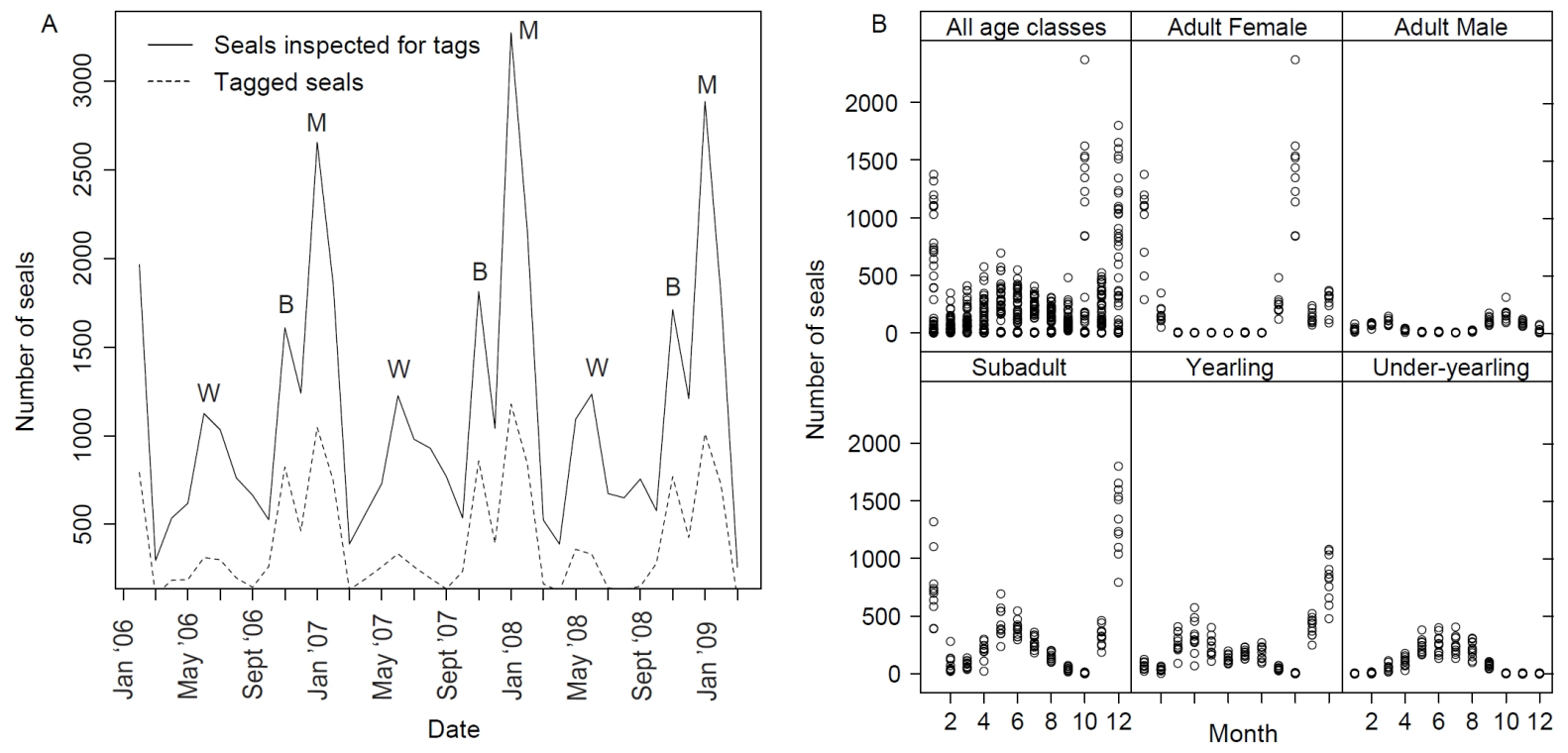
Figure 3. Monthly fluctuation in tag-ratios (proportion of tagged southern elephant seals) at Marion Island. For the purpose of this figure, a year begins in September (the start of the female breeding haulout) and ends in August. The horizontal line at 0.378 indicates the overall mean annual tag-ratio. Horizontal boxplot lines show the median tag-ratio for each month and boxes represent the $25^{\text {th }}$ and $75^{\text {th }}$ percentiles, respectively. The vertical dashed lines show either the maximum value or 1.5 times the interquartile range of the data (whichever is the smaller). Outliers are plotted individually. Data were collected monthly from May 1997 to April 2009, excluding $2002(n=11)$.

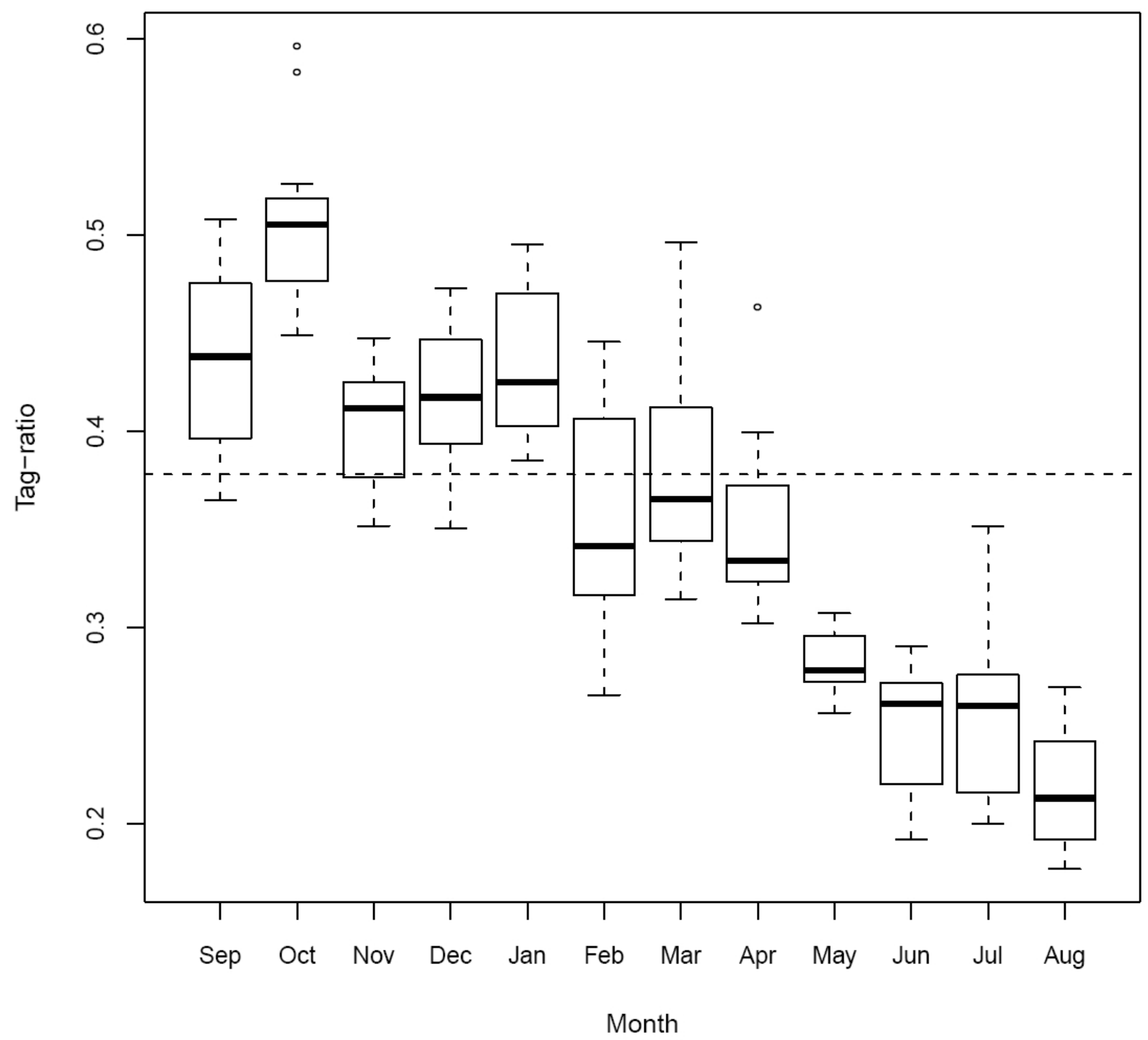


Figure 4. The distribution of tag-ratios (proportion of tagged southern elephant seals) in relation to age class. Resights of marked and unmarked seals during all haulout phases are considered.

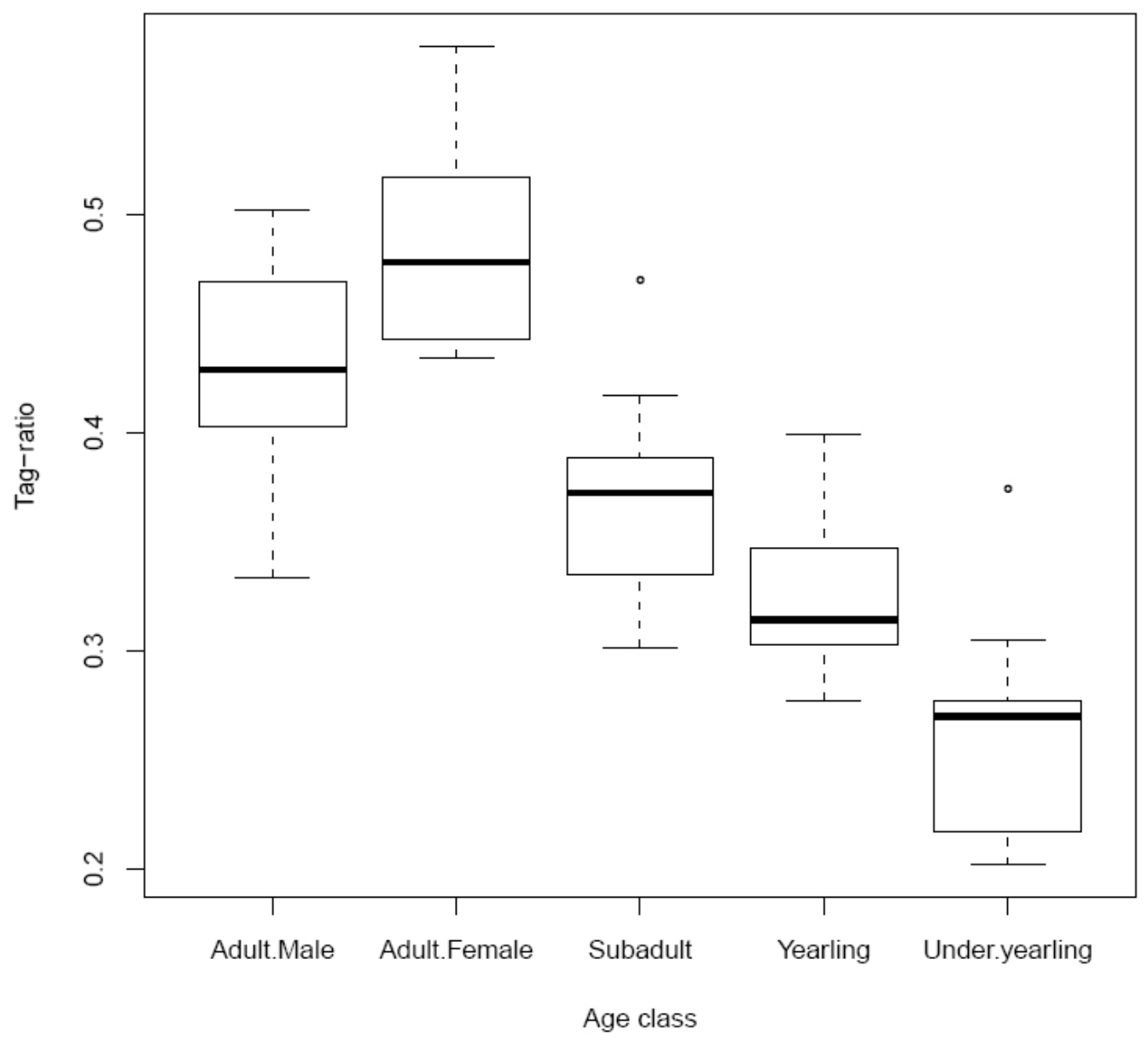


Figure 5. Southern elephant seal tag-ratios (proportion of individuals tagged) at Marion Island from May 1997 to April 2009 (excluding 2002, $n=11$ ). Mean observed proportions (points) and fitted probabilities (lines, GLM model) for different age groups (excluding adult males) are shown.
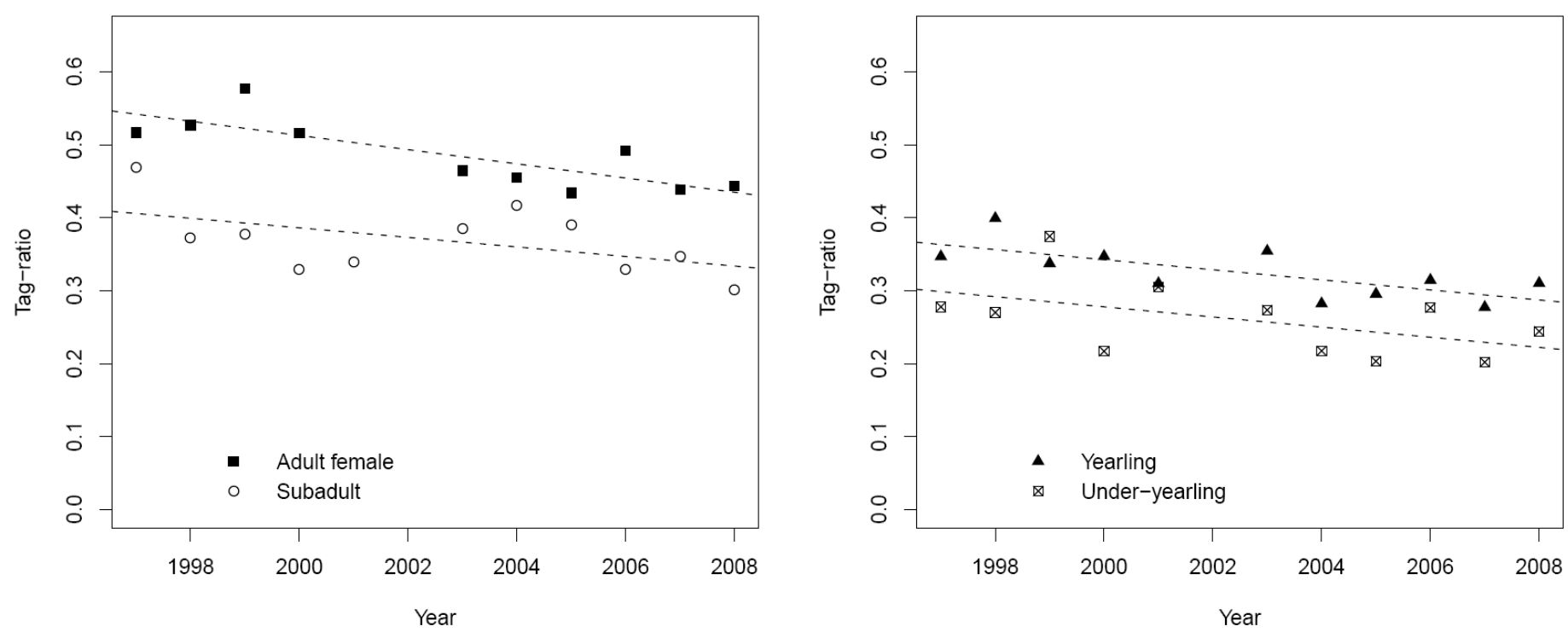
Figure 6. Variation in tag-ratios between Marion Island sites where more than 100 elephant seals were recorded during all seasons from May 1997 to April 2009. The map shows the location of sites along the Marion Island coastline with numerical codes corresponding to the "Site" axis in the histogram. Sites were categorized as having tag-ratios below (clear), similar to (grey) or above (black) the mean island wide tag-ratio of 0.378 .

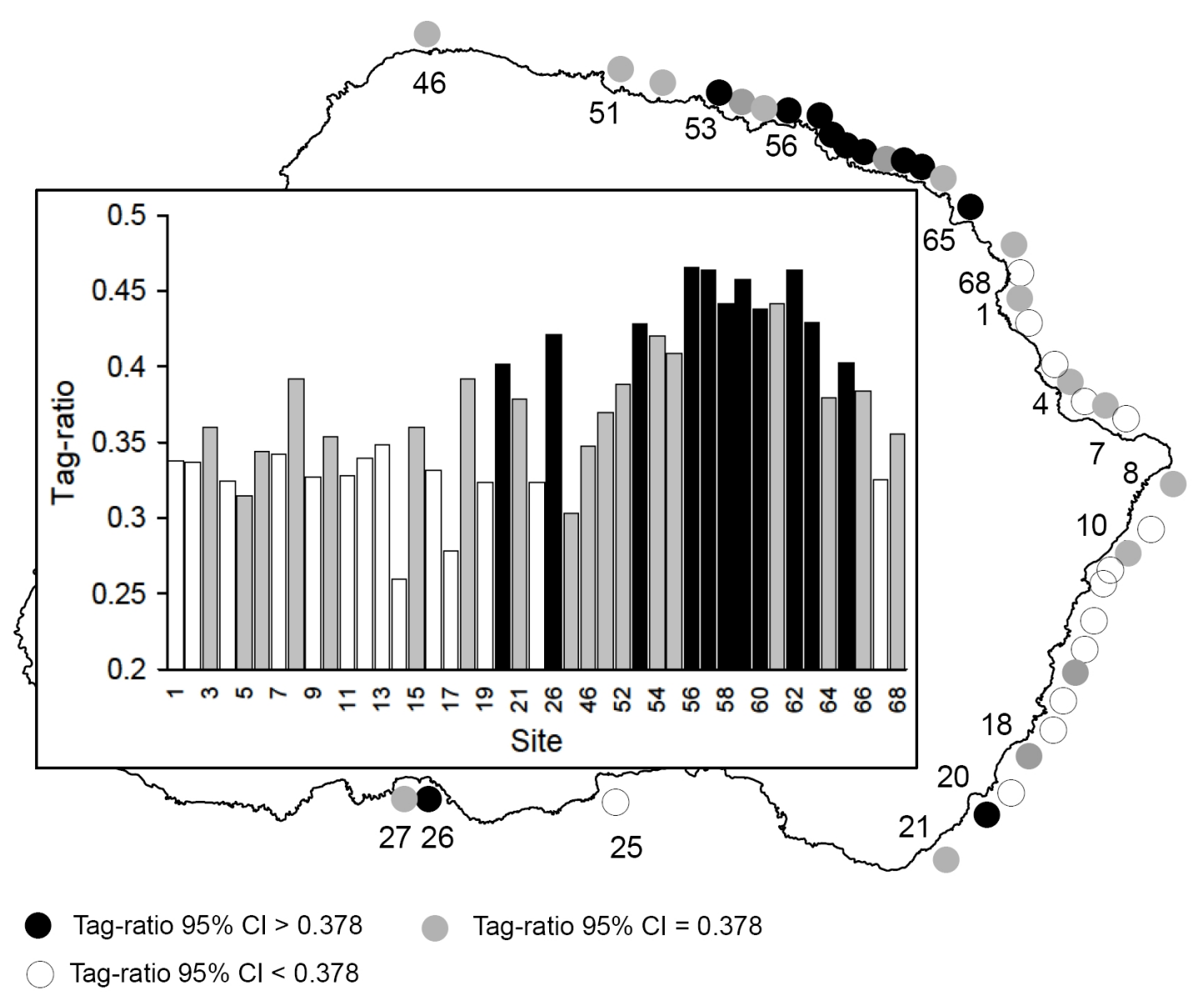


Figure 7. a. The total number of seals that utilizes a site plotted against the tag-ratio (proportion of tagged individuals) recorded for that site. The relationship is non-significant. $b$. The proportion of seals recorded per age class (relative use of a site by each age class) for sites with tag-ratios above and below 0.378 respectively. Sites with tag-ratios above 0.378 have a higher proportion of adult seals and less juvenile seals that utilize the site, as compared to sites with tag-ratios below 0.378 .

A

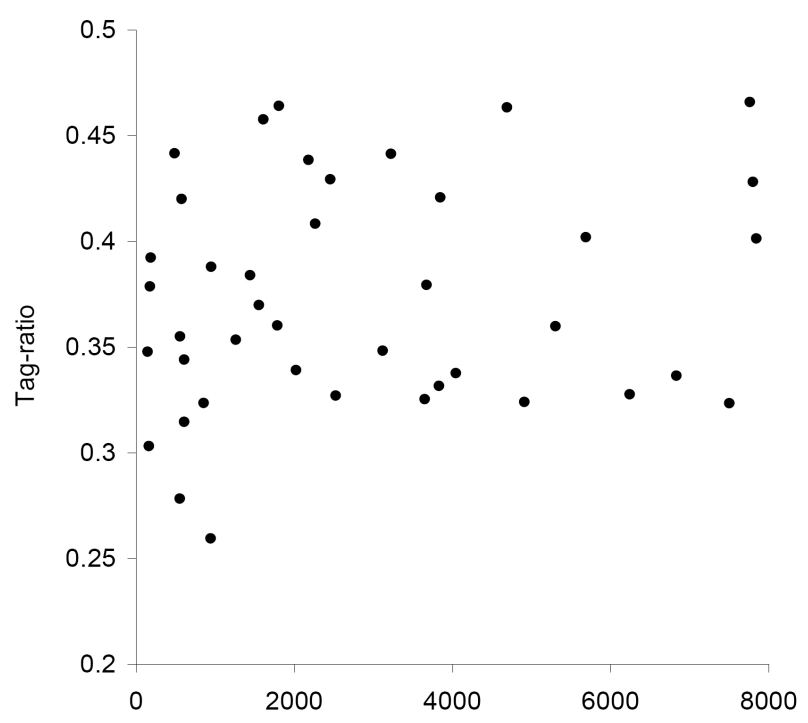

B

Number of seals

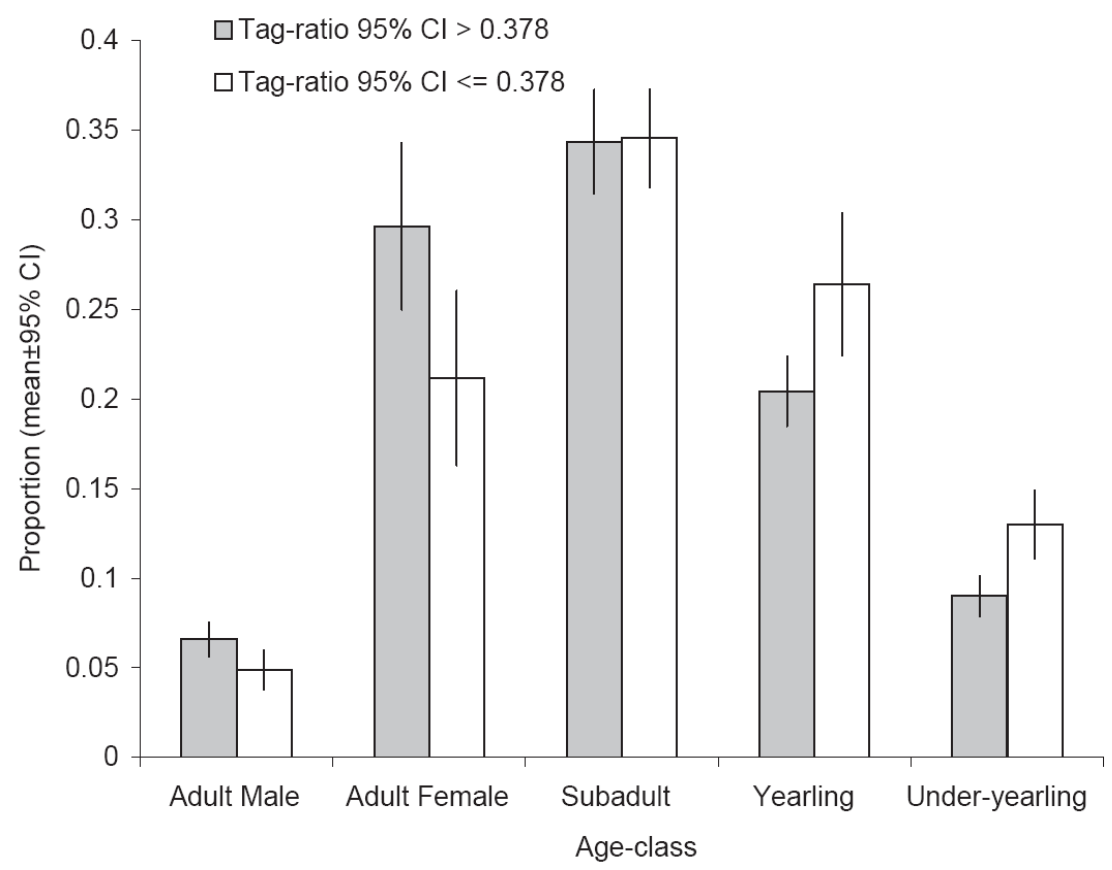

